\title{
Psychiatric Facility
}

National Cancer Institute

\section{Source}

National Cancer Institute. Psychiatric Facility. NCI Thesaurus. Code C53536.

A place designed and staffed to house and treat individuals that need assistance with mental dysfunctions. 